\title{
A Fast Retrieval of Cloud Parameters Using a Triplet of Wavelengths of Oxygen Dimer Band around $477 \mathrm{~nm}$
}

\author{
Haklim Choi ${ }^{1, *(\mathbb{D}}$, Xiong Liu ${ }^{2}\left(\mathbb{D}\right.$, Gonzalo Gonzalez Abad ${ }^{2}$, Jongjin $\mathrm{Seo}^{3}$, Kwang-Mog Lee ${ }^{1}\left(\mathbb{D}\right.$ and Jhoon Kim ${ }^{4}(\mathbb{D}$ \\ 1 Department of Astronomy and Atmospheric Sciences, Kyungpook National University, Daegu 41566, Korea; \\ kmlee@knu.ac.kr \\ 2 Harvard-Smithsonian Center for Astrophysics, 60 Garden Street, Cambridge, MA 02138, USA; \\ xliu@cfa.harvard.edu (X.L.); ggonzalezabad@cfa.harvard.edu (G.G.A.) \\ 3 Department of Astronomy and Atmospheric Sciences, University of Wisconsin, Madison, WI 53706, USA; \\ jseo47@wisc.edu \\ 4 Department of Atmospheric Sciences, Yonsei University, Seoul 03722, Korea; jkim2@yonsei.ac.kr \\ * Correspondence: haklim84@knu.ac.kr; Tel.: +82-53-950-6360
}

Citation: Choi, H.; Liu, X.;

Gonzalez Abad, G.; Seo, J.; Lee, K.-M.; Kim, J. A Fast Retrieval of Cloud Parameters Using a Triplet of Wavelengths of Oxygen Dimer Band around $477 \mathrm{~nm}$. Remote Sens. 2021, 13, 152. https://doi.org/10.3390/ rs13010152

Received: 17 November 2020 Accepted: 31 December 2020 Published: 5 January 2021

Publisher's Note: MDPI stays neutral with regard to jurisdictional clai$\mathrm{ms}$ in published maps and institutional affiliations.

Copyright: (C) 2021 by the authors. Licensee MDPI, Basel, Switzerland. This article is an open access article distributed under the terms and conditions of the Creative Commons Attribution (CC BY) license (https:// creativecommons.org/licenses/by/ $4.0 /)$.
Abstract: Clouds act as a major reflector that changes the amount of sunlight reflected to space. Change in radiance intensity due to the presence of clouds interrupts the retrieval of trace gas or aerosol properties from satellite data. In this paper, we developed a fast and robust algorithm, named the fast cloud retrieval algorithm, using a triplet of wavelengths $(469,477$, and $485 \mathrm{~nm})$ of the $\mathrm{O}_{2}-\mathrm{O}_{2}$ absorption band around $477 \mathrm{~nm}$ (CLDTO4) to derive the cloud information such as cloud top pressure (CTP) and cloud fraction (CF) for the Geostationary Environment Monitoring Spectrometer (GEMS). The novel algorithm is based on the fact that the difference in the optical path through which light passes with regard to the altitude of clouds causes a change in radiance due to the absorption of $\mathrm{O}_{2}-\mathrm{O}_{2}$ at the three selected wavelengths. To reduce the time required for algorithm calculations, the look-up table (LUT) method was applied. The LUT was pre-constructed for various conditions of geometry using Vectorized Linearized Discrete Ordinate Radiative Transfer (VLIDORT) to consider the polarization of the scattered light. The GEMS was launched in February 2020, but the observed data of GEMS have not yet been widely released. To evaluate the performance of the algorithm, the retrieved CTP and CF using observational data from the Global Ozone Monitoring Experiment-2 (GOME-2), which cover the spectral range of GEMS, were compared with the results of the Fast Retrieval Scheme for Clouds from the Oxygen A band (FRESCO) algorithm, which is based on the $\mathrm{O}_{2}$ A-band. There was good agreement between the results, despite small discrepancies for low clouds.

Keywords: fast retrieval; cloud top pressure; cloud fraction; oxygen dimer; GEMS; FRESCO; VLIDORT

\section{Introduction}

Clouds play an important role as a reflector that causes change in the amount of reflected sunlight in the ultraviolet-visible (UV-Vis) region. Moreover, clouds significantly attenuate the polarization of the atmosphere [1-3]. Thus, clouds affect the accuracy of the retrieval of trace gases and aerosols from satellites. In particular, considering the spatial resolution of satellites, only $5-15 \%$ of the observed pixels correspond to clear sky conditions [4].

Consequently, it is essential to provide cloud information for the pixels where cloud exists. For example, the amount of ozone under cloud is corrected using the climatic value since the cloud serves as a shield preventing sunlight from penetrating the atmosphere under the cloud [5,6]. Therefore, it is necessary to obtain accurate cloud information to calculate the amount of ozone precisely.

In the past, the methods for observing the composition of trace gases in the atmosphere were developed based on the instruments onboard the low Earth orbit (LEO) satellites 
such as the Ozone Monitoring Instrument (OMI [7]), Global Ozone Monitoring Experiment (GOME [8]), GOME-2 [9,10], and Scanning Imaging Absorption Spectrometer for Atmospheric Chartography (SCIAMACHY [11]). These measure the solar radiance that is reflected by the Earth at the top of the atmosphere (TOA) to monitor the atmospheric composition of interest. In recent years, many organizations have contributed to the development of geostationary Earth orbit (GEO) satellites such as Tropospheric Emissions: Monitoring of Pollution (TEMPO) [12], Sentinel-4 [13], and the Geostationary Environment Monitoring Spectrometer (GEMS) [14,15]. The goal of the constellation project using these satellites is to monitor global air quality such as the long-range transport of aerosols and the emission of pollutants in high spatiotemporal resolution [16]. Among them, GEMS was launched in February 2020 with a planned 10-year lifetime. GEMS observes the reflected radiance from the Earth in the UV-Vis region from $300-500 \mathrm{~nm}$, with a resolution of $0.6 \mathrm{~nm}$ and a spectral sampling of $0.2 \mathrm{~nm}[14,15]$.

Cloud information, cloud top pressure (CTP), and cloud fraction (CF) can be derived from the observed radiance. GOME, GOME-2, and SCIAMACHY use the oxygen A-band (in the three windows of 758-759, 760-761, and 765-766 nm) to obtain information on clouds very rapidly using the Fast Retrieval Scheme for Clouds from the Oxygen A-band (FRESCO) algorithm $[17,18]$. Additionally, an algorithm using the oxygen B-band (in the three windows: 685-686, 686.8-687.8, and 690-691 nm) has been developed [19]. Obtaining cloud information using a fast scheme can be supplied in the step of near real time (NRT), which can be used to correct or mask the cloud regions in other retrieval algorithms. Due to the spectral coverage of GEMS (300-500 nm), there is a limitation in the retrieval of cloud information using the strong absorption A- and B-bands of oxygen as they are utilized by the FRESCO algorithm. Therefore, an alternative to FRESCO is necessary to acquire fast cloud information using GEMS spectral information. There are two methods to obtain cloud information without using oxygen bands. The first method is to use the filling-in effect on the Fraunhofer lines by rotational Raman scattering (RRS) at 345 to $354 \mathrm{~nm}$, named OMCLDRR [20], and the other method is the Differential Optical Absorption Spectroscopy (DOAS) method using the absorption of $\mathrm{O}_{2}-\mathrm{O}_{2}$, named OMCLDO2 [21,22]. The OMCLDO2 algorithm is based on the assumption of the mixed Lambertian equivalent reflectivity (MLER) for the cloud treatment. In order to derive the CTP and CF, OMCLDO2 was used to perform a DOAS fit between 460 and $490 \mathrm{~nm}$, and the look-up table (LUT) inversion technique was applied from the continuum reflectance at $477 \mathrm{~nm}$ and $\mathrm{O}_{2}-\mathrm{O}_{2}$ slant column density (SCD). These two methods provide the cloud parameter information such as the operational level 2 cloud products of the OMI. Furthermore, an advanced spectral fitting method based on the $\mathrm{O}_{2}-\mathrm{O}_{2}$ absorption band using Geometry-dependent Lambertian Equivalent Reflectivity (GLER), similar to OMCLDO2, was developed. In this new version of the OMCLDO2 algorithm [23], temperature dependence correction of $\mathrm{O}_{2}-\mathrm{O}_{2}$ was applied based on DOAS fitting of [21,22]. Additionally, the method of removing outliers from the spectral fitting was implemented, and the number of nodes for surface albedo and surface pressure of LUT were increased.

In this study, we developed a novel fast and robust cloud retrieval algorithm using triplet of wavelengths of the $\mathrm{O}_{2}-\mathrm{O}_{2}$ absorption band around $477 \mathrm{~nm}$. The algorithm is based on the absorption difference of the $\mathrm{O}_{2}-\mathrm{O}_{2}$ due to the change of photon penetration, which depends on the CTP. This algorithm is similar to the previous algorithms in that it uses the $\mathrm{O}_{2}-\mathrm{O}_{2}$ absorption band [21-23], but it differs in that it applies the peak/wing ratio of radiance at three selected wavelengths. A detailed description of the algorithm is presented in Section 3. In Section 4, the retrieval results of the proposed algorithm for the CTP and CF are evaluated in comparison with the results obtained with FRESCO using GOME-2 observation data.

\section{Instrument and Data}

GOME-2 is the nadir-scanning UV-Vis spectrometer onboard the MetOp series (MetOp A, B, and C) of satellites. The MetOp satellites observe the entire Earth in a sun-synchronous 
orbit at an altitude of $820 \mathrm{~km}$ and overpass the equator at approximately 09:30 local time (LT). The principal purpose of this sensor is to monitor not only the total column amount of ozone, but also the trace gases in the atmosphere around the world for research related to air pollution and climate change. GOME-2 measures the backscattered radiance from the Earth and solar irradiance between 240 and $790 \mathrm{~nm}$ in four Main Science Channels (MSC). Moreover, GOME-2 measures the polarization state of the signal backscattered by the atmosphere simultaneously using the Polarization Measurement Device (PMD). Since GOME-2 is a polarization-sensitive instrument, the radiometric polarization calibration of MSCs is performed using measurement information from the PMD. PMD measures a lower spectral resolution than the MSCs, but it has a higher spatial resolution, which is then utilized to determine the sub-pixels of cloud cover for the MSCs [10]. GOME-2 covers the entire Earth within 1.5 days with a swath width of $1920 \mathrm{~km}$. The horizontal spatial resolution is $80 \times 40 \mathrm{~km}^{2}$ at a nadir-viewing point. The specifications of the GOME-2 instrument are summarized in Table 1. For more details on the instrument characteristics of GOME-2, refer to [10].

Table 1. Specifications of the Global Ozone Monitoring Experiment-2 (GOME-2) instrument.

\begin{tabular}{ccc}
\hline & \multicolumn{2}{c}{ GOME-2/MetOp-B } \\
\cline { 2 - 3 } Parameter & Main Science Channel (MSC) & $\begin{array}{c}\text { Polarization Measurement } \\
\text { Device (PMDs) }\end{array}$ \\
\hline Spectral Range & $239-791 \mathrm{~nm}$ & $312-790 \mathrm{~nm}$ \\
Spectral Sampling & $0.12-0.21 \mathrm{~nm}$ & $0.62-8.8 \mathrm{~nm}$ \\
Spectral Resolution & FWHM $0.29-0.55 \mathrm{~nm}$ & FWHM $2.9-37 \mathrm{~nm}$ \\
Spatial Resolution & $80 \times 40 \mathrm{~km}$ & $10 \times 40 \mathrm{~km}$ \\
Swath Width & & $1920 \mathrm{~km}$ \\
\hline
\end{tabular}

In this study, we used GOME-2/MetOp-B Level 1B (L1B) channel 3 data covering 395 to $604 \mathrm{~nm}$ with a spectral resolution of $0.55 \mathrm{~nm}$ for the retrieval of the cloud parameters. In the default scan mode scenario, the GOME-2 scan mirror sweeps from negative (east) to positive (west) viewing angles and then returns to negative viewing angles (see Figure 5 of [10]). Due to this scan pattern, we only used forward scan mode data to avoid overlapping points in the observed data.

The derived cloud information in this study, CTP and CF, was evaluated with the FRESCO+ (hereafter, FRESCO) cloud algorithm from the GOME-2 measurement (FRESCO data are available at http: / / www.temis.nl/fresco/). In many previous studies on the retrieval of cloud information, the results of FRESCO were validated with other cloud algorithms and ground-based observation, and its accuracy has been verified. For example, [17] compared the cloud parameters from Along-Track Scanning Radiometer 2 (ATSR-2) with GOME FRESCO; [18] compared Atmospheric Radiation Measurement (ARM) active ground-based remote sensing cloud boundaries data and SCIAMACHY FRESCO; and [19] compared GOME-2 FRESCO with the Cloudnet level 2 classification product composed of the vertical Doppler cloud radar and backscatter lidar. They showed good agreement with each comparison target of the FRESCO algorithm.

\section{Methodology}

\subsection{Retrieval Algorithm}

The principal atmospheric components that absorb sunlight in the UV-Vis region are ozone $\left(\mathrm{O}_{3}\right)$, sulfur dioxide $\left(\mathrm{SO}_{2}\right)$, nitrogen dioxide $\left(\mathrm{NO}_{2}\right)$, formaldehyde $(\mathrm{HCHO})$, bromine monoxide $(\mathrm{BrO})$, water vapor $\left(\mathrm{H}_{2} \mathrm{O}\right)$, and aerosols. In addition to these trace gases, absorption occurs broadly due to the collisions between oxygen molecules, which are named oxygen dimers (hereafter, $\mathrm{O}_{2}-\mathrm{O}_{2}$ ) [24,25]. The absorption cross-sections of the oxygen dimer are shown in Figure 1. As can be seen in Figure 1, there are several strong absorption bands centered at 344.0, 360.7, 380.2, 446.7, and $477.0 \mathrm{~nm}$ within the 300-500 nm spectral range, the strongest of which occurred at around $477 \mathrm{~nm}$ with a full width at half maximum $(F W H M)=5.39 \mathrm{~nm}($ at 293K) [26]. At wavelengths outside of 460 and $490 \mathrm{~nm}$ 
of the absorption band of $477 \mathrm{~nm}$, the absorption effect of $\mathrm{O}_{2}-\mathrm{O}_{2}$ is very small and can be negligible.

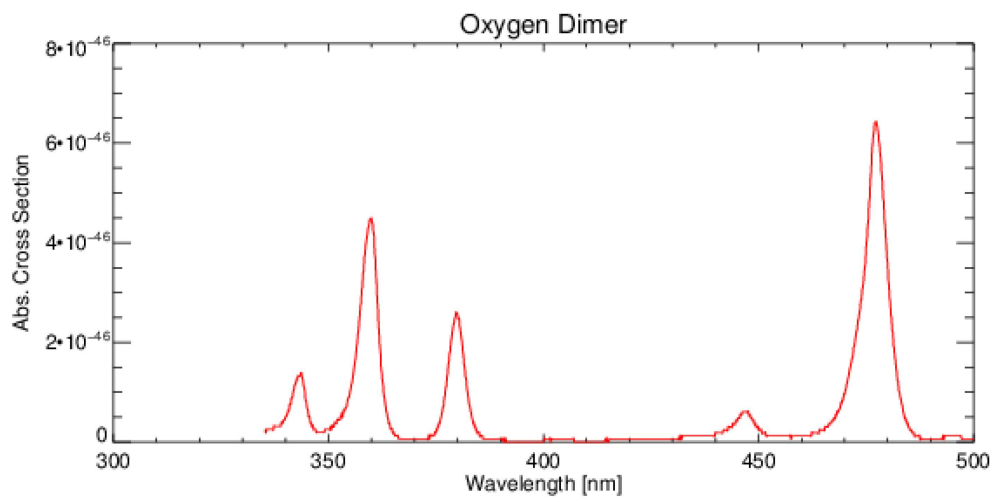

Figure 1. Absorption cross-sections of the oxygen dimer at $293 \mathrm{~K}$ determined from [27].

The cloud pressure retrieved using the $\mathrm{O}_{2}-\mathrm{O}_{2}$ absorption band refers to the optical center of the cloud [15]. A fast cloud retrieval algorithm using a triplet of wavelengths of the $\mathrm{O}_{2}-\mathrm{O}_{2}$ band around $477 \mathrm{~nm}$ (hereafter, CLDTO4) regards the top surface of the cloud as a Lambertian equivalent reflector and derives the cloud information. CLDTO4 assumes that the influence of aerosols in the atmosphere is very small compared to that of clouds and ignores the effect of aerosols in the retrieval process. When the atmosphere contains pollutants such as dust, biomass burning, or volcanic ash, these aerosols act as absorbing materials. In such cases, CTP misrecognizes a cloudless area as a cloud or underestimates it.

Our new CLDTO4 algorithm is similar to other current cloud retrieval algorithms [21-23] that are based on the $\mathrm{O}_{2}-\mathrm{O}_{2}$ absorption band at $477 \mathrm{~nm}$ and use the LUT inversion approach to retrieve the cloud parameters. However, CLDTO4 differs in that it uses peak/wing ratio information at only three wavelengths without the need to perform spectral fitting of wide $\mathrm{O}_{2}-\mathrm{O}_{2}$ absorption bands or match $\mathrm{O}_{2}-\mathrm{O}_{2}$ SCD like the other algorithms from the DOAS method. This reduces the time required for the calculation of the retrieval algorithm.

The CF can be determined using the independent pixel approximation (IPA) method [21,27] as follows:

$$
C_{f}(\lambda)=\frac{I(\lambda)-I_{c l r}\left(\lambda, A_{s f c}, P_{s f c}\right)}{I_{c l d}\left(\lambda, A_{c l d}, P_{c l d}\right)-I_{c l r}\left(\lambda, A_{s f c}, P_{s f c}\right)}
$$

where $I, A$, and $P$ are the normalized radiance signal (hereafter, NRS) at wavelength $(\lambda)$, albedo, and pressure, respectively. $I(\lambda)$ is the observed NRS by the satellite. NRS is determined as TOA radiance divided by solar irradiance. The subscripts $s f c, c l r$, and $c l d$ represent the state of the surface, clear, and cloud, respectively. $A_{s f c}$ and $A_{c l d}$ denote the albedo of the ground surface and cloud. $P_{s f c}$ and $P_{c l d}$ denote the surface pressure and CTP, respectively. The IPA method assumes that in a given pixel observed by a satellite, there exists a cloudless surface and a cloudy region, and they are weighted by the corresponding radiance. With the consideration of the plane-parallel atmosphere, it is assumed that there is no transport of photons in the horizontal direction, and radiative transfer is only in the vertical direction [27]. In other words, the CF can be determined as the ratio of the measured radiance at the satellite and the theoretically calculated cloud radiance by RTM, which removes the clear sky surface contribution.

CLDTO4 uses the following three-wavelength positions to determine the cloud effect: $477 \mathrm{~nm}$, which has the strongest absorption effect of $\mathrm{O}_{2}-\mathrm{O}_{2} ;$ and 469 and $485 \mathrm{~nm}$ on either side of the $\mathrm{O}_{2}-\mathrm{O}_{2}$ absorption band, which are hardly affected by the $\mathrm{O}_{2}-\mathrm{O}_{2}$ absorption by clouds. Hereafter, $477 \mathrm{~nm}$ is named 'peak=core', and 469 and $485 \mathrm{~nm}$ are named 'wings'. The amount of absorption by $\mathrm{O}_{2}-\mathrm{O}_{2}$ changes depending on the length of the 
optical path through which sunlight passes. Consequently, the presence of clouds can lead to a difference in radiances between the peak and wings. The average of both wings $\left(I_{\text {wing }}\right)$ and the ratio of the peak to the wings $(R)$ are defined as follows:

$$
\begin{gathered}
I_{\text {wing }}=\left(I_{469}+I_{485}\right) / 2 \\
R=I_{477} / I_{\text {wing }}
\end{gathered}
$$

where $I_{469}, I_{477}$, and $I_{485}$ are the normalized radiance values at 469,477 , and $485 \mathrm{~nm}$, respectively. Figure 2 shows that the change of $R$ depends on the average of the wing radiance for various geometric angles. These values were calculated using the radiative transfer model, which is described in the next section. The sensitivity test for the variation of solar zenith angle (SZA) and viewing zenith angle (VZA) was performed. The RAA and total column amount of ozone were fixed as $90^{\circ}$ and 325 Dobson units (DU), respectively. The SZA and VZA varied from $15^{\circ}$ to $40^{\circ}$, and $75^{\circ}$. The average wing radiance represents the reflectivity (solid lines in Figure 2) of the observed pixel from the satellite, and $R$ refers to the influence of the CTP (dotted lines in Figure 2). Each line in Figure 2 corresponds to the values of the nodes presented in Table 2. From Figure 2, it can be noticed that $R$ is less sensitive to changes in reflectivity and changes linearly with changes in surface pressure. As the altitude at which sunlight is reflected by the cloud decreases (and thus as the surface pressure of the cloud increases), $R$ decreases. $R$ becomes close to 1 when the amount of air molecules over the cloud decreases as the altitude of the cloud is high, approaching the tropopause. In addition, as the SZA increases, the slant optical path through which sunlight passes increases. Therefore, the fluctuation width of $R$ is larger than those of lower SZA. At low surface reflectivity $(<0.1)$, changes due to surface pressure are sharp. This can become a source of error for low-elevation clouds or for pixels with low fractional cloud cover.
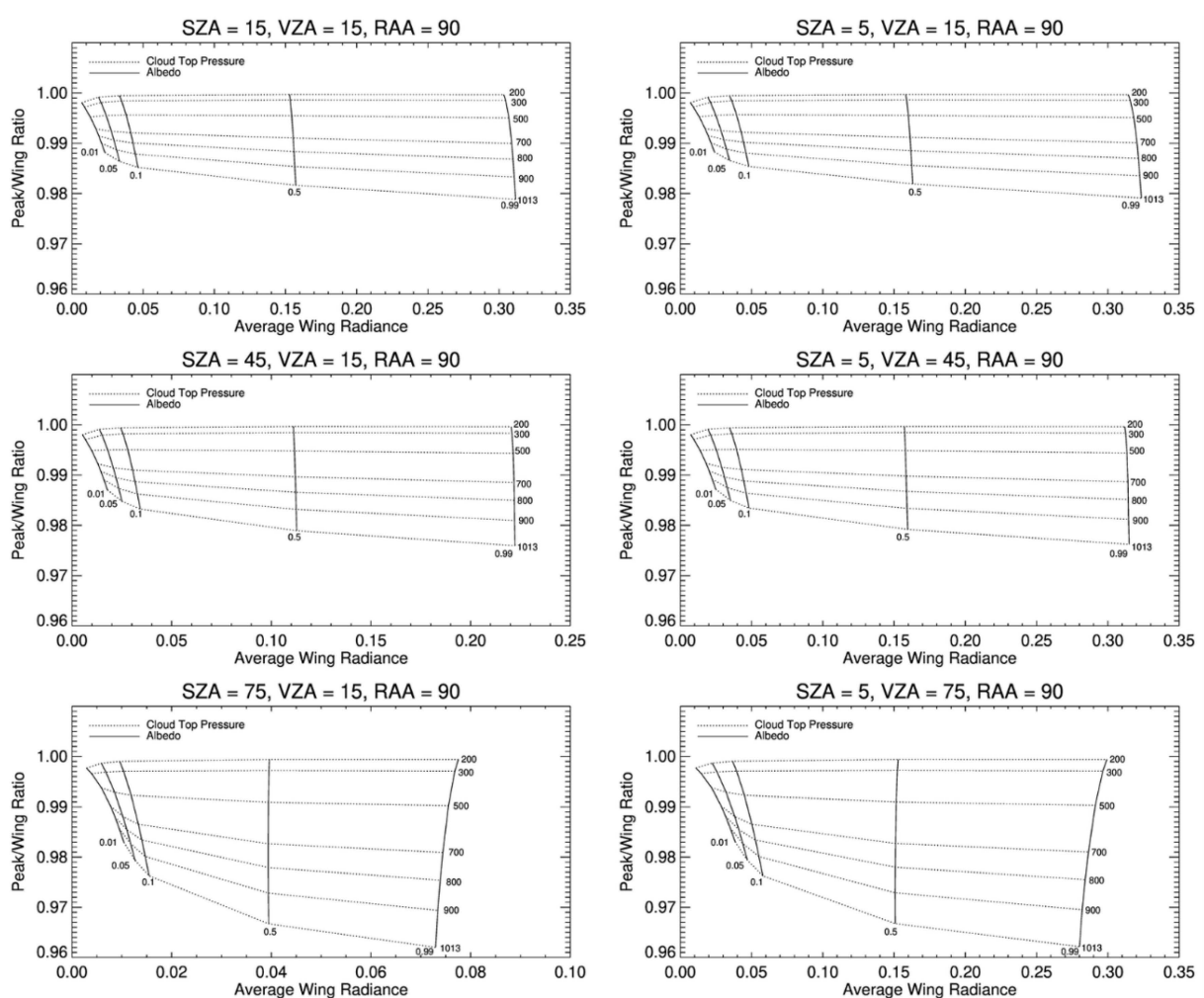

Figure 2. Change of peak/wing ratio according to average wing radiance for various geometric angles. The solid lines indicate a surface albedo of $0.01,0.05,0.1,0.5$, and 0.99 (from left to right), and the dotted lines indicate the cloud top pressure (CTP) of 1013, 900, 800, 700, 500, 300, and $200 \mathrm{hPa}$ (from bottom to top), respectively. 
Table 2. Summary of parameters and nodes used to construct the look-up table (LUT).

\begin{tabular}{cc}
\hline Parameter (Unit) & Nodes \\
\hline Wavelength (nm) & $469,477,485$ \\
SZA $\left({ }^{\circ}\right)$ & $0.1,15,30,45,60,75,85.9$ \\
VZA $\left(^{\circ}\right)$ & $0.1,15,30,45,60,75,85.9$ \\
RAA $\left(^{\circ}\right)$ & $0.1,30,60,90,120,150,179.9$ \\
Surface albedo & $0.01,0.05,0.1,0.5,0.99$ \\
Surface pressure (hPa) & $1013,900,800,700,500,300,200$ \\
Ozone profiles (DU) & L225, L275, L325, L375, L425, L475, M175, M225, \\
\hline L and M indicate low-latitude $\left(<30^{\circ}\right)$ and mid-latitude $\left(>30^{\circ}\right)$.
\end{tabular}

\subsection{Description of Look-Up Table (LUT)}

The LUT method is an effective way to save computation time when simulating the satellite-observed radiance, as it takes a long time to calculate using the radiative transfer model in real-time. For this purpose, the LUT was prepared for several parameters affecting radiance. Radiance was pre-calculated using Vectorized Linearized Discrete Ordinate Radiative Transfer (VLIDORT; $[28,29]$ ) as a function of SZA, VZA, RAA, surface albedo, surface pressure, and ozone profiles. The atmospheric condition is assumed to be a molecular atmosphere without aerosols. The radiative transfer model (RTM) simulation was executed in vector mode to account for the polarization effect. This is because the failure to consider polarization in the simulation of scalar mode can cause an error of up to $10 \%$ at the TOA $[30,31]$. The atmospheric profiles (i.e., temperature, humidity, and gases) were adopted from the Air Force Geophysics Laboratory (AFGL) atmospheric constituent databases for the United States standard atmosphere 1976 (US76; [32]). The calculation included absorption by $\mathrm{O}_{3}, \mathrm{NO}_{2}$, and $\mathrm{O}_{2}-\mathrm{O}_{2}$. For $\mathrm{NO}_{2}$, a fixed profile (total amount of $\mathrm{NO}_{2}$ was $0.215 \mathrm{DU}$ ) was applied to the RTM simulation. The ozone profiles were constructed based on Version 8 (V8) of the Total Ozone Mapping Spectrometer (TOMS) climatology data [5]. These profiles were classified into low-latitude (L) and midlatitude (M) depending on the location of the latitude with regard to the total column amount of ozone. The threshold for distinguishing between mid and low latitudes was $30^{\circ}$ south/north latitude. The LUT contains seven nodes of SZA, seven nodes of VZA, and seven nodes of RAA. The angles of step size of SZA, VZA, and RAA were $15^{\circ}, 15^{\circ}$, and $30^{\circ}$, respectively. Surface albedo and surface pressure were calculated for five and seven nodes, respectively. Two-thirds of the Earth is covered by sea, which has low reflectivity in visible regions $[33,34]$. The surface at high-latitude regions or high mountainous areas covered with snow or ice has high reflectivity. This means that most regions of the Earth, except the permafrost and polar regions, have relatively low reflectivity. Therefore, the step size of the LUT is constructed smaller increments at relatively low reflectivity values (less 0.1 ) and more sparsely at higher values. The parameter nodes are summarized in Table 2.

\section{Results}

\subsection{CLDTO4 Retrievals from GOME-2 Observation}

We applied CLDTO4 to GOME-2 data to evaluate the performance. The cloud parameters were retrieved by CLDTO4 on 20 September 2016, a randomly selected date. The variables (i.e., total column amount of ozone, surface pressure, and surface reflectivity), except for the radiance and geometry of the satellite used in CLDTO4, were adopted by climatology data.

The observed TOA radiance of each pixel consisted of the clear sky sub-pixel and the CF weighted cloud sub-pixel as described in Equation (1). In order to know the contribution of the clear sky, we require the information of $A_{s f c}$ and $P_{s f c}$. We adopted the GOME-2 Lambertian Equivalent Reflectivity (LER) database [35] with a resolution of $0.25^{\circ} \times 0.25^{\circ}$ to consider the temporal and spatial variation of the surface reflectivity. The surface reflectivity was interpolated to $477 \mathrm{~nm}$ and applied to $A_{s f c}$. We used the Earth 
TOPOgraphy (ETOPO)-2 dataset [36] to obtain the terrain height information. The ETOPO2 dataset was generated from digital databases of seafloor and land elevations on a 2-minute latitude/longitude grid. The coverage of ETOPO-2 is $90^{\circ} \mathrm{S}$ to $90^{\circ} \mathrm{N}$ in latitude, and $180^{\circ} \mathrm{W}$ to $180^{\circ} \mathrm{E}$ in longitude. In order to consider only the surface altitude, the submarine region with a negative value was replaced with zero. The terrain height was converted to $P_{s f c}$ using the following barometric formula.

$$
P_{s f c}=P_{0} \exp ^{(-z / H)}
$$

where $P_{0}$ is the sea level pressure $(1013.25 \mathrm{hPa}) ; z$ is the altitude at the level; and $H$ is the scale height. The scale height was assumed to be $8 \mathrm{~km}$. $R$ and $I_{\text {wing }}$ were calculated using Equations (2) and (3), respectively, from the radiance of the three selected wavelengths $(469,477$, and $485 \mathrm{~nm})$ observed in each individual pixel of GOME-2. The pre-constructed LUT was multi-dimensionally interpolated to the values of input variables (SZA, VZA, RAA, and total column amount of ozone) given at each pixel. At this time, the total column amount of ozone was adopted from the McPeters and Labow (ML) climatology data [37] (seasonal ozone profile merged data composed of Aura Microwave Limb Sounder (MLS) and ozone sonde data at intervals of $10^{\circ}$ from $-90^{\circ} \mathrm{S}$ to $+90^{\circ} \mathrm{N}$ ). The total column amount of ozone was applied by integrating the amount of ozone in each vertical layer. $P_{c l d}$ and $C_{f}$ could be obtained from the optimized values that satisfied the calculated $R$ and $I_{\text {wing }}$ from the LUT. The retrieved CTP and CF by CLDTO4 are illustrated in Figure 3a,b.
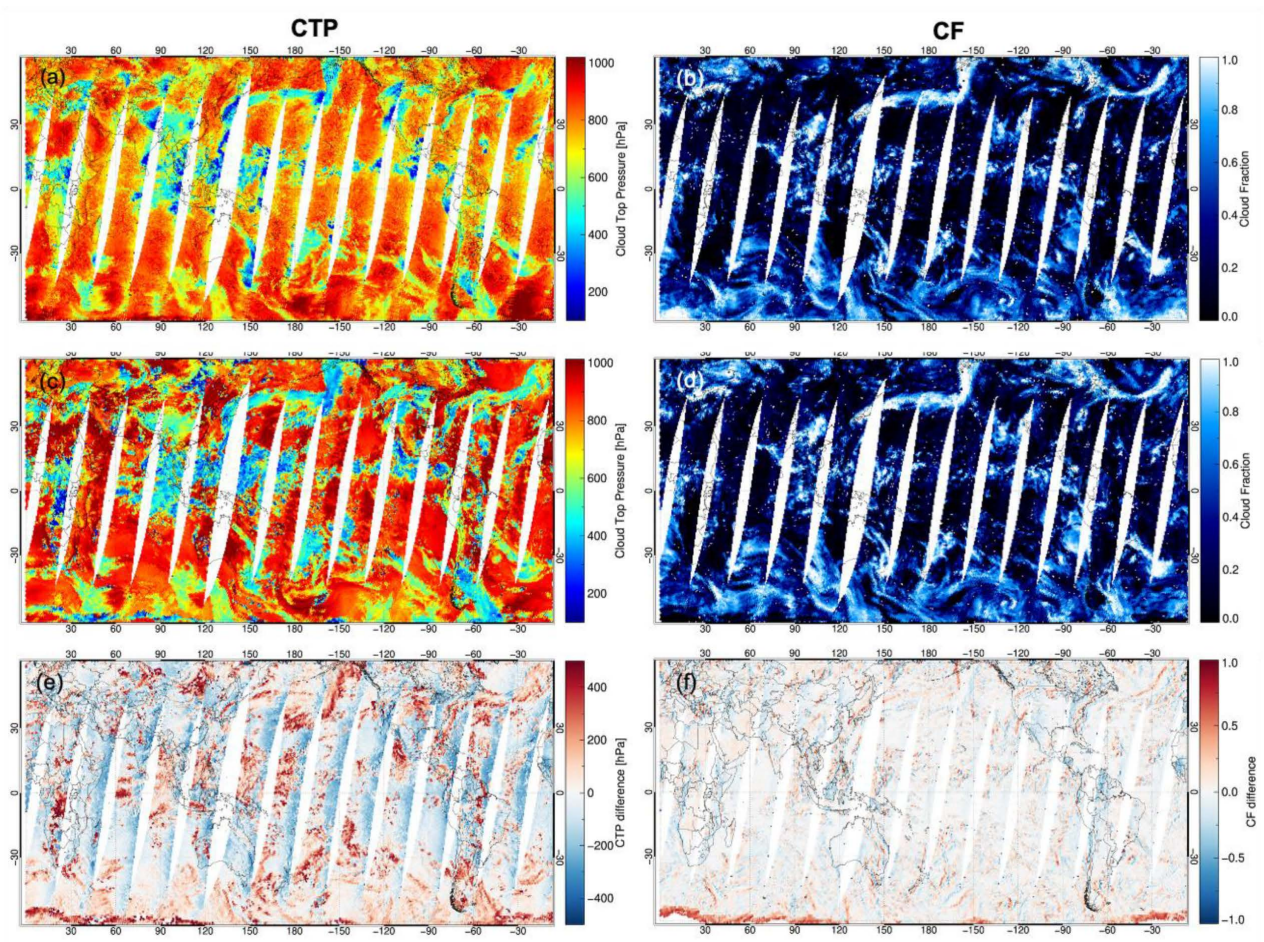

Figure 3. Retrieval result of CTP and cloud fraction (CF) by $(\mathbf{a}, \mathbf{b})$ fast cloud retrieval algorithm using a triplet of wavelengths of the $\mathrm{O}_{2}-\mathrm{O}_{2}$ band around $477 \mathrm{~nm}$ (CLDTO4), (c,d) Global Ozone Monitoring Experiment-2 (GOME-2) Fast Retrieval Scheme for Clouds from the Oxygen A band (FRESCO), and (e,f) difference between CLDTO4 and FRESCO on 20 September 2016.

\subsection{Inter-Comparison of Cloud Parameters with Fast Retrieval Scheme for Clouds from the} Oxygen A Band (FRESCO)

The CTP and CF were compared with the values retrieved from GOME-2 FRESCO to verify the performance of CLDTO4. As mentioned earlier, FRESCO applies a nonlinear fitting method based on the $\mathrm{O}_{2}-\mathrm{A}$ absorption band at $760 \mathrm{~nm}$, and not a DOAS method such as OMI. An additional difference between CLDTO4 and FRESCO is that the wavelength 
applied by approximating the surface reflectance data is $760 \mathrm{~nm}$ for FRESCO and $477 \mathrm{~nm}$ for CLDTO4. The surface reflectivity in the visible region is higher over desert and evergreen forest than in the ultraviolet region and lower over ocean [34,35,38-40]. FRESCO, which uses the visible region, has a high sensitivity to the variation of radiance with the reflectance by surface type. Since GOME-2 FRESCO is also a result of the retrieval algorithm rather than an actual in situ observation, it is difficult to consider as a true value for cloud information. Nevertheless, the mutual comparison of these two algorithms is meaningful for the purpose of analyzing the difference between the $\mathrm{O}_{2}-\mathrm{O}_{2}$ method of CLDTO4 and the $\mathrm{O}_{2}$-A method of FRESCO in the retrieval of the cloud parameters and to evaluate the performance of CLDTO4.

Figure 3 shows the retrieved results for CTP and CF from both algorithms on 20 September 2016. The CTP results retrieved from CLDTO4 and FRESCO are shown in Figure 3a,c, respectively; CFs are shown in Figure 3b,d, respectively. The differences between the two retrieval algorithms (CLDTO4-FRESCO) are illustrated in Figure 3e,f. Overall, the qualitative behavior of both algorithms detecting cloud regions was very similar. The negative differences between the two algorithms occurred in the region where the VZA of GOME-2 was large, at the right edge of the cross-track (see Figure 3e). The CTP of FRESCO was relatively low on the right side of the along-track direction of GOME-2. The mean value of the negative difference that occurred on the right side of the alongtrack was $-115 \pm 87.87 \mathrm{hPa}$. This is noticeable where the derived CTP is close to $1 \mathrm{~atm}$ (1013.25 hPa). CLDTO4 tends to treat the CTP slightly lower for clear sky or low-altitude clouds. This is because the low radiance intensity is very sensitive to the variation of CTP, as mentioned in the previous section. However, these differences can be ignored because most of these areas correspond to clear sky, which has a very low CF $(<0.2)$. CLDTO4 overestimates the CTP in the tropical and sub-tropical regions with respect to FRESCO (see Figure 3c). This means that when the fraction of clouds occupied by pixels is small in tropical or sub-tropical regions, FRESCO is retrieved as a relatively high cloud compared to CLDTO4. Figure 4 presents CTP and CF as probability distribution functions (PDFs) for CLDTO4 and FRESCO. The CTP distribution peak of CLDTO4 occurred at around $800 \mathrm{hPa}$, whereas that of FRESCO occurred at $850 \mathrm{hPa}$. The center of the distribution of FRESCO was skewed toward lower cloud pressure with respect to CLDTO4, which means that CLDTO4 is considered a rather lower pressure for low-altitude cloud compared to FRESCO. In contrast, FRESCO sees a greater proportion of CTP than CLDTO4 at above $600 \mathrm{hPa}$. In pixels where clouds exist (CF > 0.1), FRESCO treats clouds at a slightly higher percentage than CLDTO4. In contrast, CLDTO4 has a high proportion at almost clear sky $(\mathrm{CF}<0.1)$. Figure 5 shows a boxplot of the distribution of $\mathrm{CTP}$ along the range of $\mathrm{CF}$ in each algorithm. CF was divided from 0 to 1 with 0.1 intervals. When $C F$ was between 0 and 0.1 (i.e., an almost clear sky pixel), the maximum cloud height was $550 \mathrm{hPa}$ for CLDTO4, compared to $100 \mathrm{hPa}$ for FRESCO. In CLDTO4, the range of cloud height steadily increased as CF increased, while FRESCO obtained high-altitude clouds (close to $200 \mathrm{hPa}$ ) in all CF ranges. This means that FRESCO treats the cloud as higher for the optically thin fractional cloud or transparent cloud. Meanwhile, for the section of CF from 0-0.1 to 0.9-10, the median CTP of CLDTO4 gradually decreased, with small fluctuations from 789.2 to $709.6 \mathrm{hPa}$. On the other hand, FRESCO decreased, dramatically from 803.6 to $642.3 \mathrm{hPa}$, as CF increased. This indicates that FRESCO considers clouds higher-altitude clouds when the percentage of clouds within the pixel is high. CF showed good agreement, as the difference between the two algorithms was very small. Unlike CTP, there was no bias characteristic due to the observation geometry. 

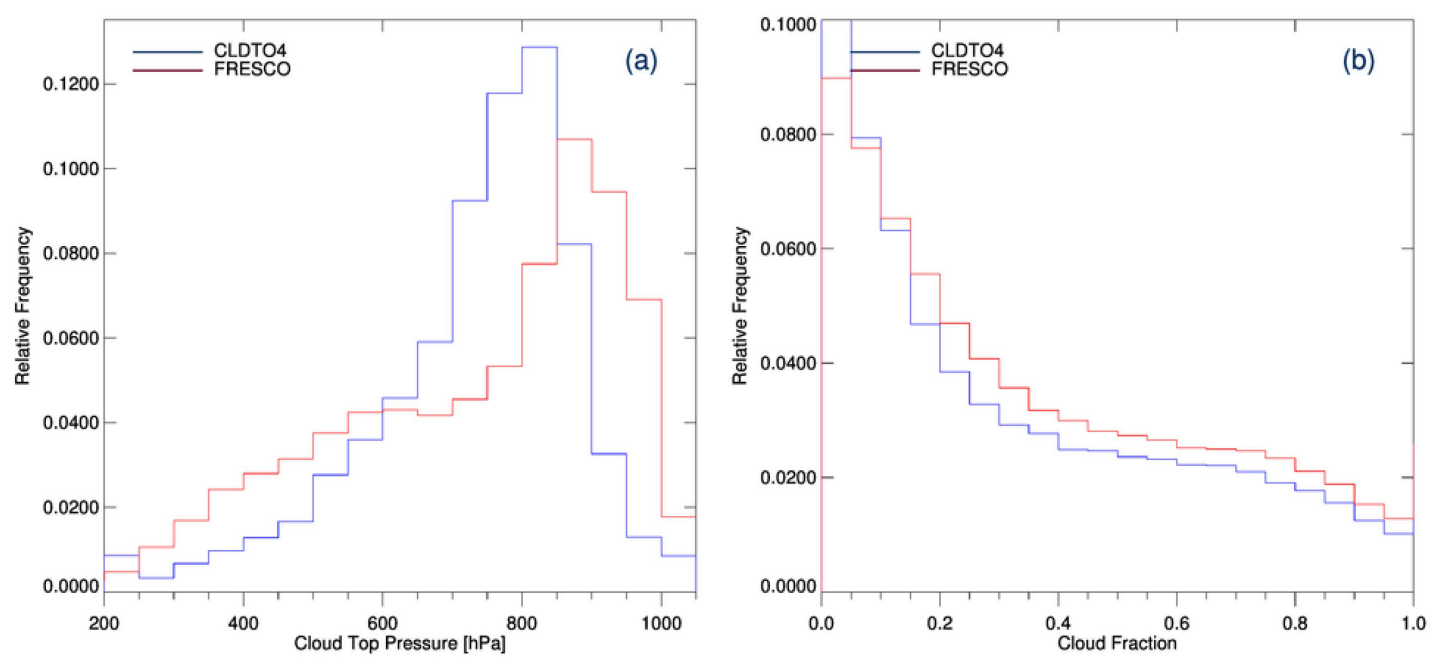

Figure 4. Probability distribution of (a) CTP and (b) CF by CLDTO4 and FRESCO.
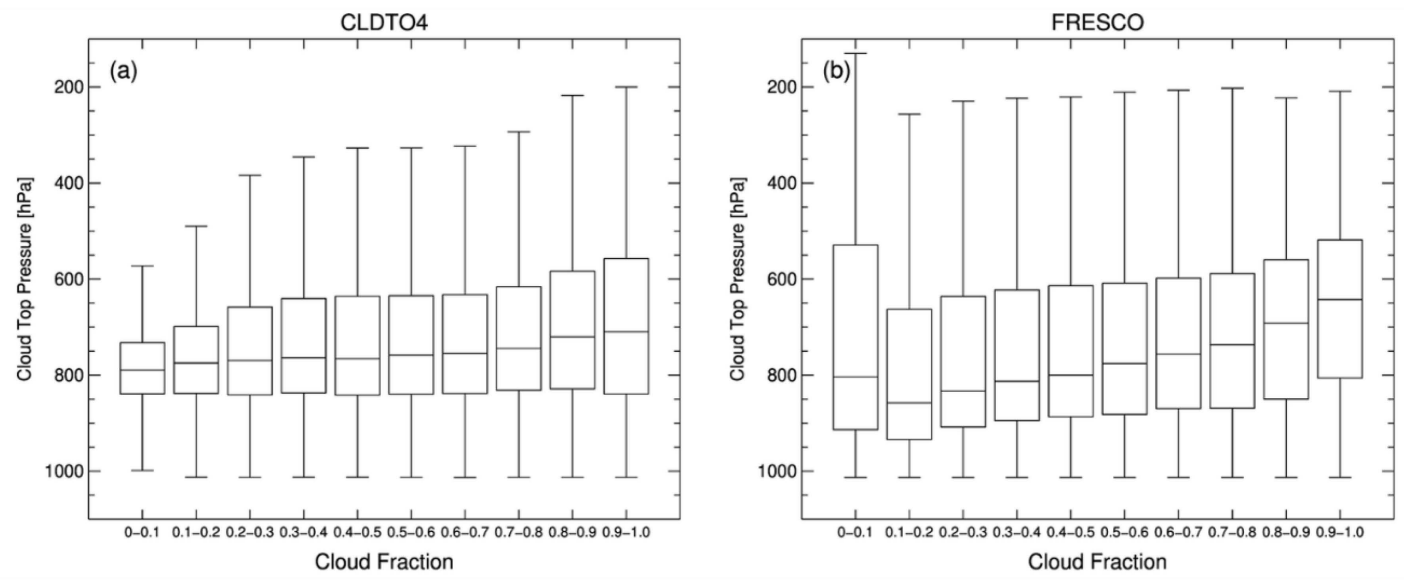

Figure 5. Boxplot of distribution of CTP as function of CF for each cloud retrieval algorithm: (a) CLDTO4 and (b) FRESCO.

Figure 6 shows an example of the cross-section of CTP and CF as a function of latitude for each calculation algorithm. The variation of latitude indicates the location of satellite pixels along the GOME-2 flight direction. Although there were some discrepancies, the tendency of the CTP and CF of both algorithms for the cloud region was very similar. As above-mentioned, between the latitude of $20^{\circ} \mathrm{S}$ to $20^{\circ} \mathrm{N}$ (tropical and sub-tropical regions), there were features in which CLDTO4 tended to assign the CTP as higher than FRESCO for low clouds and slightly lower for high clouds. FRESCO detects the clouds as high altitude at the edges of several consecutive cloud distributions. In this GOME-2 track line, the mean differences (CLDTO4-FRESCO) of CTP and CF between CLDTO4 and FRESCO were $29 \pm 163.59 \mathrm{hPa}$ and $0.19 \pm 0.67$, respectively.

Figure 7 presents the comparison of the results between CLDTO4 and FRESCO for CTP and CF as a histogram of bias and a density scatterplot. These are the results for all of the outputs from the GOME-2 observations shown in Figure 3. As mentioned earlier, the CTP retrieved by CLDTO4 tended to be underestimated in the clear region $(\mathrm{CF}<0.2)$ compared to FRESCO. In particular, the difference wase up to $100 \mathrm{hPa}$ for low clouds, where FRESCO's CTP is $800-900 \mathrm{hPa}$ (Figure $7 \mathrm{~b}$ ). The retrieved values of CF obtained using CLDTO4 were very similar to those retrieved using FRESCO, except in some high-latitude regions with bright surfaces. This is because a ground surface with high reflectivity (e.g., snow or ice) can be mistaken for clouds. Both algorithm results for CF almost followed the 1:1 line, although the CF of FRESCO was slightly large. The biases in CTP and CF had a Gaussian distribution. The statistical results for CTP and CF are summarized in Table 3. For 
all sky, in the case of CTP, the correlation coefficient, bias, root mean square error (RMSE), and mean absolute error (MAE) were $0.74,-3.56,77.5$, and 34.75 , respectively. For $\mathrm{CF}$, the correlation coefficient, bias, RMSE, and MAE were $0.67,0.11,0.11$, and 0.05 , respectively. Furthermore, where the presence of clouds was significant (CF $>50 \%$ ), the two algorithms showed better agreement. The correlation coefficient, bias, RMSE, and MAE for CTP were $0.79,-2.32,48.61$, and 15.56 , respectively. This indicates that the CLDTO4 method provides cloud information with a high level of accuracy that matches that of FRESCO.
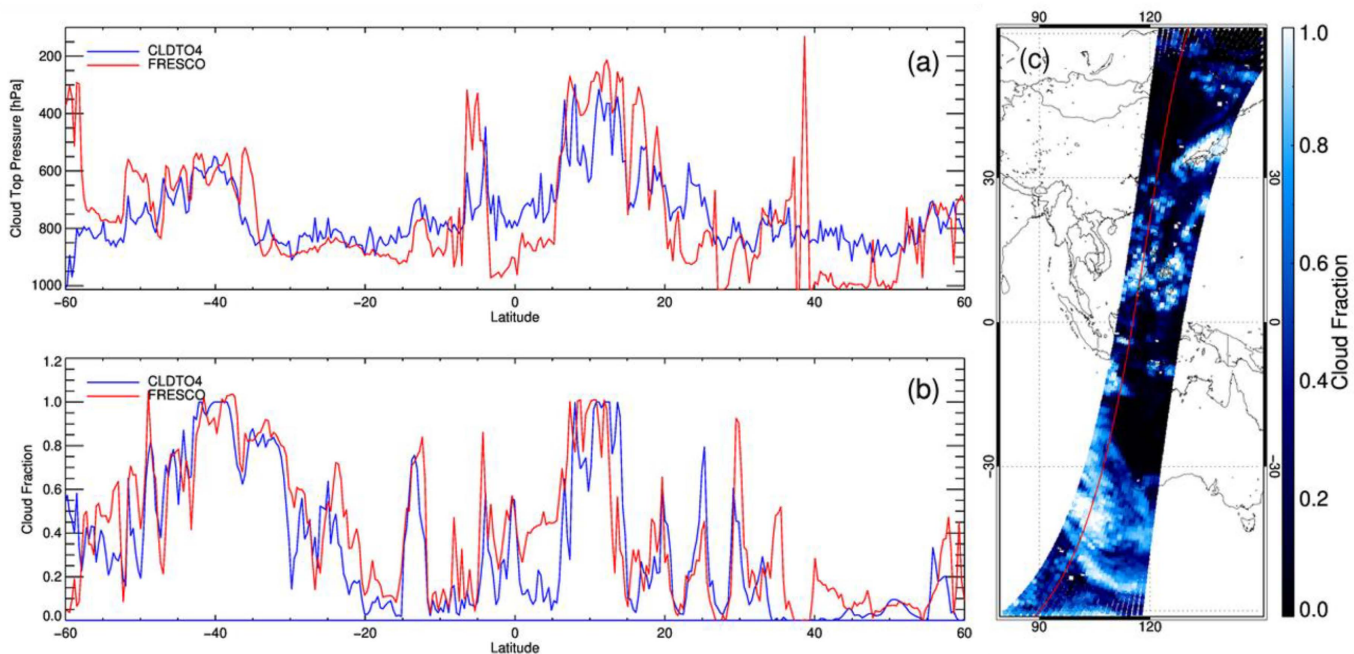

Figure 6. Intercomparison of (a) CTP and (b) CF was retrieved from CLDTO4 and FRESCO. The cross-section is a GOME-2 orbit as a function of the latitude from 0108 to 0250 UTC on 20 September 2016. (c) The trajectory of the over-passed track of GOME-2. The track line used in $(\mathbf{a}, \mathbf{b})$ is represented as a red line. The overlapped background image is the CF of CLDTO4.
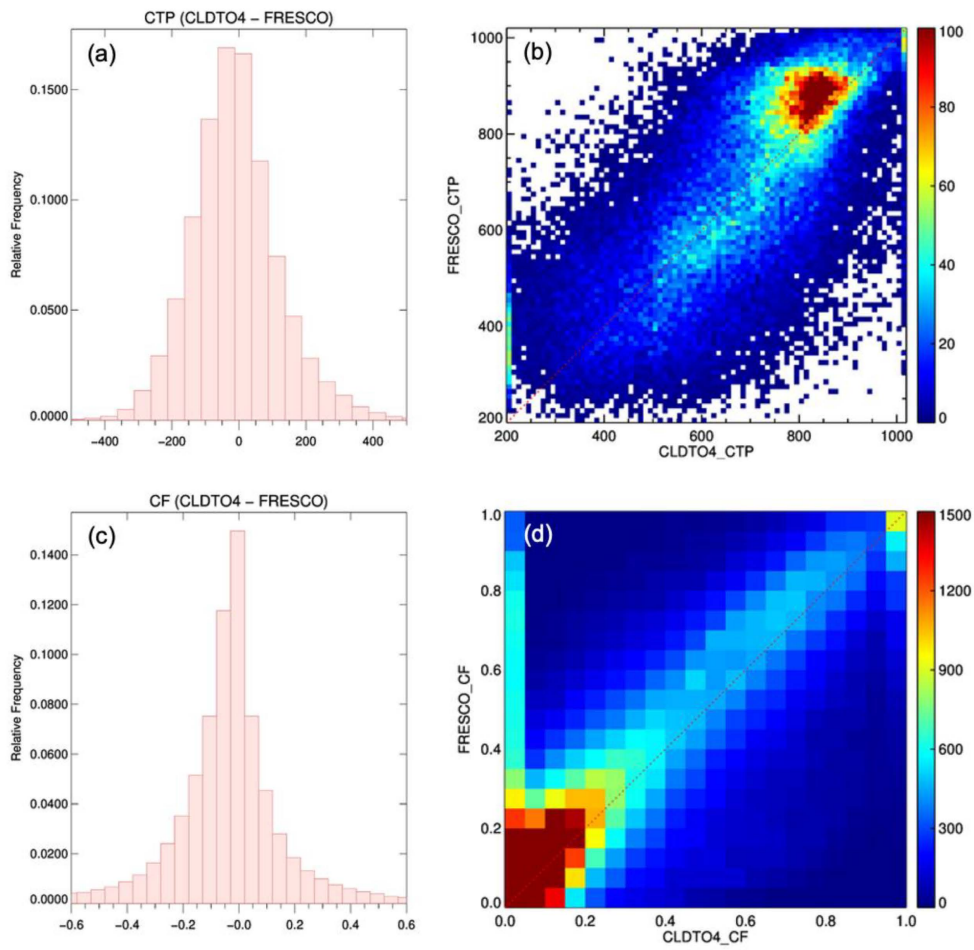

Figure 7. (a) Histogram of bias and (b) density plot for CTP. (c) Histogram of bias and (d) density plot for CF. 
Table 3. Statistical results of CTP and CF for coverage of cloud pixels in (a) all sky and (b) significant $\mathrm{CF}(>0.5)$.

\begin{tabular}{ccccc}
\hline \multirow{2}{*}{ Parameter } & \multicolumn{2}{c}{ (a) All Sky } & \multicolumn{2}{c}{ (b) CF $>\mathbf{0 . 5}$} \\
\cline { 2 - 5 } & CTP $(\mathbf{h P a})$ & CF & CTP (hPa) & CF \\
\hline Correlation & 0.74 & 0.67 & 0.79 & 0.61 \\
Coefficient & -3.56 & 0.11 & -2.32 & 0.004 \\
Bias & 77.58 & 0.11 & 48.61 & 0.06 \\
RMSE & 34.75 & 0.05 & 15.56 & 0.01 \\
MAE & &
\end{tabular}

\section{Discussion}

CLDTO4 only uses a triplet of wavelengths, unlike the spectral fitting method, which uses the whole set of wavelengths in the absorption band to derive the cloud information in a short time. Therefore, CLDTO4 is sensitive to the radiance spectral feature affected by the radiometric calibration quality and the polarization sensitivity of the instrument. This is related to the importance of securing radiometric accuracy in the L0-1 process.

CLDTO4 was developed for GEMS, but in this study, the evaluation was performed using GOME-2 data. When cloud parameters are derived by applying CLDTO4 to GEMS, cloud structure information on a smaller scale can be provided because the spatial resolution of GEMS is smaller than that of GOME-2. Both satellites observed the radiance within the wavelength range including the $\mathrm{O}_{2}-\mathrm{O}_{2}$ absorption band for utilizing the CLDTO4, but there were differences in spectral resolution, slit function, and signal-to-noise ratio (SNR), which could affect the shape of the radiance spectrum. This can lead to differences in cloud retrieval results. Furthermore, GOME-2 and GEMS are LEO and GEO, respectively. In general, the range of VZA of GEO is relatively larger than that of LEO. Since the calculation is not accurate for large VZA and SZA in the radiation transfer process, assuming a plane-parallel atmosphere, the uncertainty of the cloud retrieval result can increase in the region with large VZA of GEMS.

In this study, the cloud parameters of CLDTO4 achieved good performance as a result of comparison with FRESCO, but there remains scope for improvement in the future. For example, CLDTO4 underestimated CTP compared to FRESCO in low cloud states. In addition, one fixed $\mathrm{NO}_{2}$ profile was used in the LUT configuration. In regions where the emissions of $\mathrm{NO}_{2}$ are high, this can be a source of error in cloud retrieval. Therefore, additional correction for the amount of $\mathrm{NO}_{2}$ is needed. We constructed the LUT by assuming the Rayleigh atmosphere, which does not consider the aerosol effect. This assumption treats the amount of radiation absorbed from the atmosphere as larger for turbid atmospheres containing pollutants such as mineral dust, biomass, and volcanic ash. Then, CTP can misrecognize a cloudless area as a cloud or underestimate it. The absorption cross-section of $\mathrm{O}_{2}-\mathrm{O}_{2}$ has a temperature dependence [21,23,41]. CLDTO4 does not consider the variation of the atmospheric temperature profile to reduce temperature uncertainty. Moreover, the absorption cross-sections exist not only for $\mathrm{O}_{2}, \mathrm{NO}_{2}$, and $\mathrm{O}_{2}-\mathrm{O}_{2}$, but also for water vapor within the spectral range of GEMS, so there is potential for improving the LUT by considering water vapor.

In the future, we will apply the actual slit function of GEMS and optimize the LUT configuration to improve the proposed algorithm's accuracy, because the LUT nodes at regular intervals may cause nonlinear interpolation errors. Furthermore, we will retrieve cloud information from the measured data obtained since the GEMS was launched as well as verify the CLDTO4 with the GEMS operational cloud algorithm and cloud radar or lidar (ground-based or satellite) and continue to improve its precision.

\section{Summary and Conclusions}

Clouds play an important role in the amount of sunlight reflected out of the atmosphere. In order to produce trace gas or aerosol information with high accuracy from the 
radiance that is observed from satellites at the TOA in determining NRT, it is necessary to obtain accurate cloud information quickly. The fundamental purpose of this study was to retrieve the cloud information in a short time within the spectral region of GEMS. CLDTO4 used the absorption difference at 469, 477, and $485 \mathrm{~nm}$ concerning the optical path change depending on the presence of clouds. To reduce the calculation time, a LUT was constructed for various conditions considering the polarization effect using VLIDORT.

The results of CTP and CF retrieved by CLDTO4, developed in this study, were compared with the GOME-2 FRESCO algorithm results. There was a small discrepancy in the proposed algorithm, which underestimated the CTP of low cloud (up to $100 \mathrm{hPa}$ difference) with respect to FRESCO, but the results for CTP and CF were very similar and showed good performance. In the regions with significant $C F(>0.5)$, the correlation coefficient was 0.79 , which was 0.05 higher than the all sky condition (0.74), and the RMSE was $48.61 \mathrm{hPa}$, which was $28.97 \mathrm{hPa}$ lower than the all sky condition $(77.58 \mathrm{hPa})$. When the CF was between 0 and 0.1, which means almost clear sky, FRESCO tended to yield the clouds as higher-altitude than CLDTO4. The CLDTO4 method using the $\mathrm{O}_{2}-\mathrm{O}_{2}$ band at $477 \mathrm{~nm}$ was less sensitive to fractional clouds $(C F<0.2)$ and transparent clouds at high altitude than FRESCO. The penetration length of photons of reflected sunlight differed in two channels with different absorption characteristics such as the $\mathrm{O}_{2}-\mathrm{O}_{2}$ band and the $\mathrm{O}_{2}$-A band. Therefore, the method of using each independent absorption band can cause differences in the retrieval results for CTP. The result of CF of CLDTO4 is suitable for determination of the threshold value applied to the cloud masking of the pixel for the retrieval algorithms of trace gases such as $\mathrm{NO}_{2}, \mathrm{SO}_{2}$, and $\mathrm{HCHO}$. The slight difference of CTP that occurred in low altitude clouds compared to FRESCO could have a significant effect on correction for the amount of ozone under the cloud layer to retrieve the total amount of ozone in the cloud region. For example, if the CTP is lower than the actual value, it can be assumed that there is a greater amount of ozone under the cloud in that pixel. Then, the total ozone amount will be overestimated. Nevertheless, the cloud parameters obtained using the proposed algorithm were comparable to those obtained using FRESCO. Therefore, it is sufficient to be utilized for the retrieval of trace gases and aerosol properties.

Author Contributions: This work was made possible by significant contributions from all authors. Conceptualization, X.L. and H.C.; Methodology, H.C., X.L., and K.-M.L.; Software, H.C. and J.S.; Validation, H.C. and K.-M.L.; Formal analysis, H.C. and K.-M.L.; Investigation, H.C. and X.L.; Writing-original draft preparation, H.C.; Writing—review and editing, K.-M.L., X.L., G.G.A., and J.K.; Visualization, H.C.; Supervision, K.-M.L.; Funding acquisition, K.-M.L. and J.K. All authors have read and agreed to the published version of the manuscript.

Funding: This research was supported by the Korea Ministry of Environment (MOE) through the "Public Technology Program based on Environmental Policy (2017000160002)".

Institutional Review Board Statement: Not applicable for studies not involving humans or animals. Informed Consent Statement: Not applicable for studies not involving humans.

Data Availability Statement: The data that support the findings of this study are available from the corresponding author upon reasonable request.

Acknowledgments: The authors would like to express their gratitude to the reviewers for their valuable comments and suggestions for improving this manuscript.

Conflicts of Interest: The authors declare no conflict of interest. 


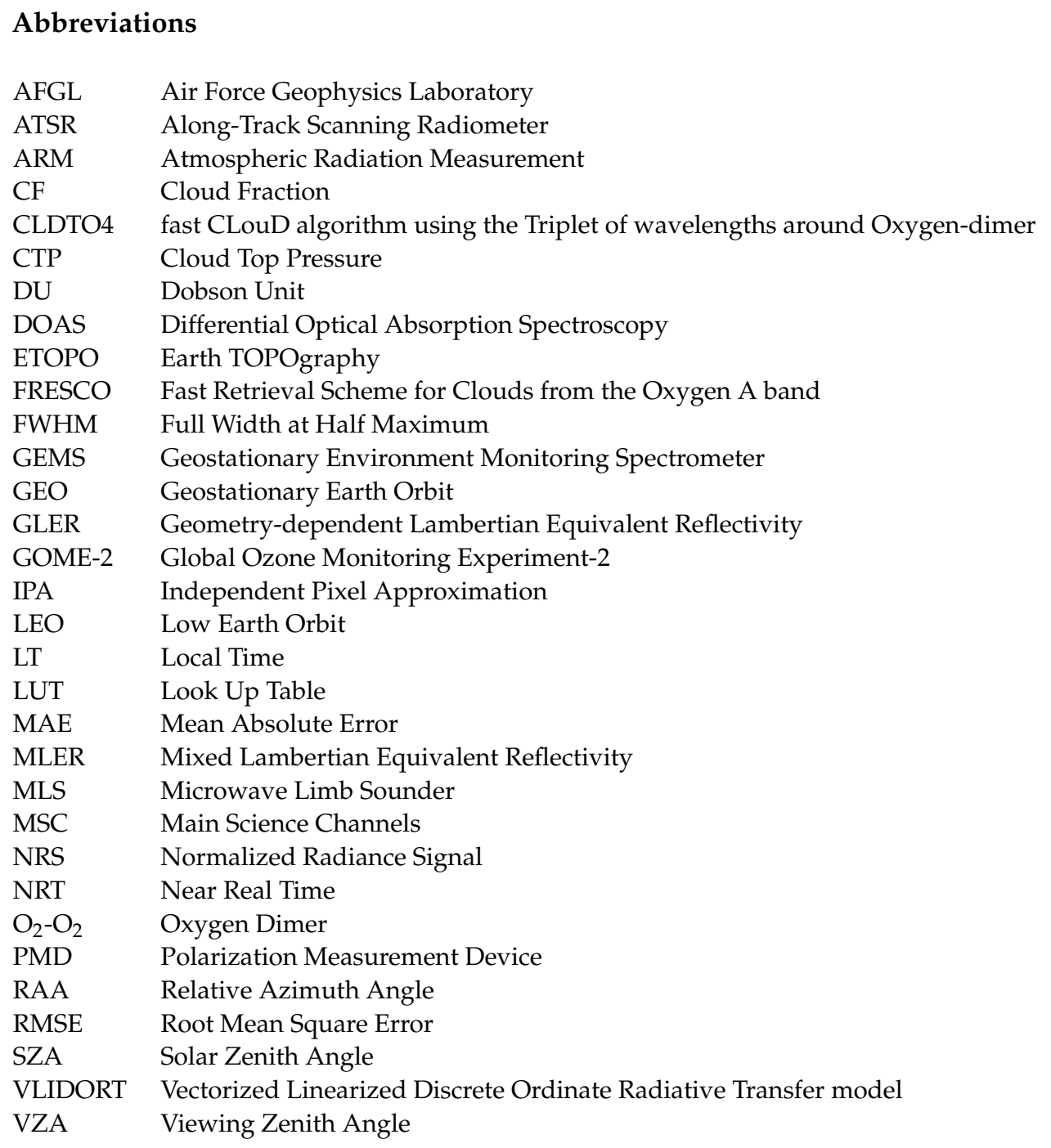

\section{References}

1. Choi, H.; Lee, K.-M.; Seo, J.; Bae, J. The Influence of Atmospheric Composition on Polarization in the GEMS Spectral Region. Asia Pac. J. Atmos. Sci. 2020. [CrossRef]

2. Emde, C.; Buras-Schnell, R.; Sterzik, M.; Bagnulo, S. Influence of aerosols, clouds, and sunglint on polarization spectra of Earthshine. Astron. Astrophys. 2017, 605, A2. [CrossRef]

3. Schutgens, N.A.J.; Tilstra, L.G.; Stammes, P.; Bréon, F.M. On the relationship between Stokes parameters Q and U of atmospheric ultraviolet/visible/near-infrared radiation. J. Geophys. Res. D Atmos. 2004. [CrossRef]

4. Krijger, J.M.; Van Weele, M.; Aben, I.; Frey, R. Technical Note: The effect of sensor resolution on the number of cloud-free observations from space. Atmos. Chem. Phys. 2007. [CrossRef]

5. Bhartia, P.K.; Wellemeyer, C.W. TOMS-V8 Total O3 Algorithm in OMI Algorithm Theoretical Basis Document; Bhartia, P.K., Ed.; NASA Goddard Space Flight Center: Greenbelt, MD, USA, 2002; Volume II, pp. 15-32. Available online: https:/ / eospso.gsfc.nasa.gov/ sites/default/files/atbd/ATBD-OMI-02.pdf (accessed on 5 November 2020).

6. Liu, X.; Bhartia, P.K.; Chance, K.; Spurr, R.J.D.; Kurosu, T.P. Ozone profile retrievals from the ozone monitoring instrument. Atmos. Chem. Phys. 2010, 10, 2521-2537. [CrossRef]

7. Levelt, P.F.; van den Oord, G.H.J.; Dobber, M.R.; Malkki, A.; Huib, V.; Johan de, V.; Stammes, P.; Lundell, J.O.V.; Saari, H. The ozone monitoring instrument. IEEE Trans. Geosci. Remote Sens. 2006, 44, 1093-1101. [CrossRef]

8. Burrows, J.P.; Weber, M.; Buchwitz, M.; Rozanov, V.; Ladstätter-Weißenmayer, A.; Richter, A.; Debeek, R.; Hoogen, R.; Bramstedt, K.; Eichmann, K.U.; et al. The Global Ozone Monitoring Experiment (GOME): Mission concept and first scientific results. J. Atmos. Sci. 1999, 56, 151-175. [CrossRef]

9. Callies, J.; Corpaccioli, E.; Eisinger, M.; Hahne, A.; Lefebvre, A. GOME-2-Metop's second-generation sensor for operational ozone monitoring. ESA Bull. 2000, 102, 28-36. 
10. Munro, R.; Lang, R.; Klaes, D.; Poli, G.; Retscher, C.; Lindstrot, R.; Huckle, R.; Lacan, A.; Grzegorski, M.; Holdak, A.; et al. The GOME-2 instrument on the Metop series of satellites: Instrument design, calibration, and level 1 data processing-An overview. Atmos. Meas. Tech. 2016, 9, 1279-1301. [CrossRef]

11. Bovensmann, H.; Burrows, J.P.; Buchwitz, M.; Frerick, J.; Noël, S.; Rozanov, V.V.; Chance, K.V.; Goede, A.P.H. SCIAMACHY: Mission objectives and measurement modes. J. Atmos. Sci. 1999, 56, 127-150. [CrossRef]

12. Zoogman, P.; Liu, X.; Suleiman, R.M.; Pennington, W.F.; Flittner, D.E.; Al-Saadi, J.A.; Hilton, B.B.; Nicks, D.K.; Newchurch, M.J.; Carr, J.L.; et al. Tropospheric emissions: Monitoring of pollution (TEMPO). J. Quant. Spectrosc. Radiat. Transf. 2017, 186, 17-39. [CrossRef] [PubMed]

13. Ingmann, P.; Veihelmann, B.; Langen, J.; Lamarre, D.; Stark, H.; Courrèges-Lacoste, G.B. Requirements for the GMES Atmosphere Service and ESA's implementation concept: Sentinels-4/-5 and -5p. Remote Sens. Environ. 2012, 120, 58-69. [CrossRef]

14. Kim, J.; Jeong, U.; Ahn, M.-H.; Kim, J.H.; Park, R.J.; Lee, H.; Song, C.H.; Choi, Y.-S.; Lee, K.-H.; Yoo, J.-M.; et al. New era of air quality monitoring from space: Geostationary environment monitoring spectrometer (GEMS). Bull. Am. Meteorol. Soc. 2020, 101, E1-E22. [CrossRef]

15. Choi, W.J.; Moon, K.-J.; Yoon, J.; Cho, A.; Kim, S.-K.; Lee, S.; Ko, D.H.; Kim, J.; Ahn, M.H.; Kim, D.-R.; et al. Introducing the geostationary environment monitoring spectrometer. J. Appl. Remote Sens. 2018, 12, 044005. [CrossRef]

16. CEOS. Geostationary Satellite Constellation for Observing Global Air Quality: Geophysical Validation Needs. 2017. Available online: http:/ / ceos.org/observations /documents/GEO_AQ_Constellation_Geophysical_Validation_Needs_1.1_2Oct2019.pdf (accessed on 5 November 2020).

17. Koelemeijer, R.B.A.; Stammes, P.; Hovenier, J.W.; De Haan, J.F. A fast method for retrieval of cloud parameters using oxygen A band measurements from the Global Ozone Monitoring Experiment. J. Geophys. Res. Atmos. 2001, 106, 3475-3490. [CrossRef]

18. Wang, P.; Stammes, P.; Van Der, A.R.; Pinardi, G.; Van Roozendael, M. FRESCO+: An improved $\mathrm{O}_{2}$ A-band cloud retrieval algorithm for tropospheric trace gas retrievals. Atmos. Chem. Phys. 2008, 8, 6565-6576. [CrossRef]

19. Desmons, M.; Wang, P.; Stammes, P.; Gijsbert Tilstra, L. FRESCO-B: A fast cloud retrieval algorithm using oxygen B-band measurements from GOME-2. Atmos. Meas. Tech. 2019, 12, 2485-2498. [CrossRef]

20. Joiner, J.; Vasilkov, A.P. First results from the OMI rotational Raman scattering cloud pressure algorithm. IEEE Trans. Geosci. Remote Sens. 2006, 44, 1272-1282. [CrossRef]

21. Acarreta, J.R.; De Haan, J.F.; Stammes, P. Cloud pressure retrieval using the $\mathrm{O}_{2}-\mathrm{O}_{2}$ absorption band at $477 \mathrm{~nm}$. J. Geophys. Res. D Atmos. 2004. [CrossRef]

22. Vasilkov, A.; Yang, E.S.; Marchenko, S.; Qin, W.; Lamsal, L.; Joiner, J.; Krotkov, N.; Haffner, D.; Bhartia, P.K.; Spurr, R. A cloud algorithm based on the $\mathrm{O}_{2}-\mathrm{O}_{2} 477 \mathrm{~nm}$ absorption band featuring an advanced spectral fitting method and the use of surface geometry-dependent Lambertian-equivalent reflectivity. Atmos. Meas. Tech. 2018, 11, 4093-4107. [CrossRef]

23. Veefkind, J.P.; De Haan, J.F.; Sneep, M.; Levelt, P.F. Improvements to the OMI $\mathrm{O}_{2}-\mathrm{O}_{2}$ operational cloud algorithm and comparisons with ground-based radar-lidar observations. Atmos. Meas. Tech. 2016, 9, 6035-6049. [CrossRef]

24. Salow, H.; Steiner, W. Die durch Wechselwirkungskräfte bedingten Absorptionsspektra des Sauerstoffes. Z. Phys. 1936, 99, 137-158. [CrossRef]

25. Janssen, J. Analyse Spectrale des Éléments de l'atmosphère Terrestre; Gauthier-Villars: Paris, France, 1885.

26. Thalman, R.; Volkamer, R. Temperature dependent absorption cross-sections of $\mathrm{O}_{2}-\mathrm{O}_{2}$ collision pairs between 340 and $630 \mathrm{~nm}$ and at atmospherically relevant pressure. Phys. Chem. Chem. Phys. 2013, 15, 15371-15381. [CrossRef] [PubMed]

27. Zuidema, P.; Evans, K.F. On the validity of the independent pixel approximation for boundary layer clouds observed during ASTEX. J. Geophys. Res. Atmos. 1998, 103, 6059-6074. [CrossRef]

28. Spurr, R.J.D. VLIDORT: A linearized pseudo-spherical vector discrete ordinate radiative transfer code for forward model and retrieval studies in multilayer multiple scattering media. J. Quant. Spectrosc. Radiat. Transf. 2006, 102, 316-342. [CrossRef]

29. Spurr, R. LIDORT and VLIDORT: Linearized pseudo-spherical scalar and vector discrete ordinate radiative transfer models for use in remote sensing retrieval problems. In Light Scattering Reviews 3; Springer: Berlin/Heidelberg, Germany, 2008.

30. Mishchenko, M.I.; Lacis, A.A.; Travis, L.D. Errors induced by the neglect of polarization in radiance calculations for Rayleighscattering atmospheres. J. Quant. Spectrosc. Radiat. Transf. 1994, 51, 491-510. [CrossRef]

31. Lacis, A.A.; Chowdhary, J.; Mishchenko, M.I.; Cairns, B. Modeling errors in diffuse-sky radiation: Vector vs. scalar treatment. Geophys. Res. Lett. 1998, 25, 135-138. [CrossRef]

32. Anderson, G.P.; Clough, S.A.; Kneizys, F.X.; Chetwynd, J.H.; Shettle, E.P. AFGL Atmospheric Constituent Profiles (0-120 km); Air Force Geophysics Laboratory: Hanscom AFB, Bedford, MA, USA, 1986.

33. Vasilkov, A.; Lyapustin, A.; Mitchell, B.G.; Huang, D. UV reflectance of the ocean from DSCOVR/EPIC: Comparisons with a theoretical model and Aura/OMI observations. J. Atmos. Ocean. Technol. 2019, 36, 2087-2099. [CrossRef]

34. Zoogman, P.; Liu, X.; Chance, K.; Sun, Q.; Schaaf, C.; Mahr, T.; Wagner, T. A climatology of visible surface reflectance spectra. J. Quant. Spectrosc. Radiat. Transf. 2016, 180, 39-46. [CrossRef]

35. Tilstra, L.G.; Tuinder, O.N.E.; Wang, P.; Stammes, P. Surface reflectivity climatologies from UV to NIR determined from Earth observations by GOME-2 and SCIAMACHY. J. Geophys. Res. 2017, 122, 4084-4111. [CrossRef]

36. NOAA National Geophysical Data Center. 2-Minute Gridded Global Relief Data (ETOPO2) v2; NOAA: Washington, DC, USA, 2006.

37. McPeters, R.D.; Labow, G.J. Climatology 2011: An MLS and sonde derived ozone climatology for satellite retrieval algorithms. J. Geophys. Res. Atmos. 2012. [CrossRef] 
38. Koelemeijer, R.B.A.; de Haan, J.F.; Stammes, P. A database of spectral surface reflectivity in the range 335-772 nm derived from 5.5 years of GOME observations. J. Geophys. Res. Atmos. 2003. [CrossRef]

39. Fournier, N.; Koelemeijer, R.B.A.; Eisinger, M.; De Haan, J.F.; Stammes, P. Refinement of a database of spectral surface reflectivity in the range 335-772 nm derived from 5.5 years of GOME observations. In Proceedings of the Envisat \& ERS Symposium (ESA SP-572), Salzburg, Austria, 6-10 September 2004.

40. Kleipool, Q.L.; Dobber, M.R.; de Haan, J.F.; Levelt, P.F. Earth surface reflectance climatology from 3 years of OMI data. J. Geophys. Res. Atmos. 2008. [CrossRef]

41. Park, S.S.; Takemura, T.; Kim, J. Effect of temperature-dependent cross sections on $\mathrm{O}_{4}$ slant column density estimation by a space-borne UV-visible hyperspectral sensor. Atmos. Environ. 2017, 152, 98-110. [CrossRef] 